\title{
Study of the Crosslinking Reaction between Bisphenol A Diglycidyl ether (BADGE) and a Zinc Porphyrin by Fourier Transform Infrared Spectroscopy.
}

Eva C. Vázquez, ${ }^{*}$ Aida Jover, ${ }^{2}$ Francisco Fraga, ${ }^{1}$ José Vázquez Tato, ${ }^{2}$ Julio A. Seijas, ${ }^{3 *}$

'Departamento de Física Aplicada. Facultade de Ciencias. Universidade de Santiago de Compostela. Campus Lugo.27080-Lugo. Spain.

2Departamento de Química Física. Facultade de Ciencias. Universidade de Santiago de Compostela. Campus Lugo.27080-Lugo.Spain.

${ }^{3}$ Departamento de Química Orgánica. Facultade de Ciencias. Universidade de Santiago de Compostela.Campus Lugo. 27080-Lugo.Spain.

\begin{abstract}
The curing reaction of a system consisting of a diglycidyl ether of bisphenol- $A(n=0)$ and ZnTPyP (Zinc 5,10,15,20-tetra(4-pyridyl)-21H,23H-porphyrin) was studied by Fourier Transform Infrared Spectroscopy (FTIR). A semi-empirical quantum chemistry program (MOPAC) was used to corroborate the experimental data. The tertiary amine ZnTPyP not only initiates the reaction but also reacts with the resin forming pyridone. This study demonstrates that macrocycles can be used as cross-linking agents forepoxy resins and that when metallomacrocycles are used, metal ions can be introduced into the network structure.
\end{abstract}

KEYWORDS: FTIR; porphyrins; epoxy resins, tertiary amines

\section{INTRODUCTION}

Epoxy resins have a position of great importance in polymer industries because of their many different applicationsindustry (electrical, naval, aerospace, construction...) as well as in sports, medicine, and so on. The great success of epoxy resins are related to their light weight compared to other materials, high mechanical characteristics, great resistance to corrosion, and the possibility of different designs for particular applications'. On the other hand, porphyrins and related compounds, such as chlorophyll andhemin, are essential to many biological energy transduction processesincluding light harvesting and photocatalytic processes ${ }^{2-5}$.For this study, the zinc meso-tetra (4-pyridyl) porphyrin (ZnTPyP, a tertiaryamine) has been chosen as the curing agent for the epoxy resin bisphenol-A diglycidyl ether ( $n=0)$ (BADGE).

The epoxy homopolymerization caused by tertiary amineshas been studiedby several authors ${ }^{6-17}$. This is a very complex process due to the concurrence of multiple reactionsinvolving at least the following steps: (1) initiation by adduct formation with transfer to hydroxyl compound; (2) propagation by any alkoxide anion present in thesystem; (3) chain transfer between any alkoxide anion and hydroxylic species and 
(4) initiation regeneration by elimination or substitution. Recovering of the tertiary amine has been frequentlyreported in the literature $8-9,14,16,18$. However,the occurrence of termination reactionswithout regeneration of the tertiary amine, leading toincomplete curing of epoxy resins 14,16 , has also been proposed.In fact, although epoxy homopolymerization with tertiary amines has been extensively studied 13-15,19-21, apparently contradictory results concerning the network formation have been reported.

This study is part of a project in which the effects of introducing macrocycles derivatives on the epoxy resinnetwork are investigated 22 . These crosslinking agents improve the stability of the resin at high temperatures, besides they have the ability to strongly bind metallic ions, forming complexes. This could lead to develop epoxy polymers with new unexpected properties.

\section{EXPERIMENTAL}

\section{Materials and Sample preparation}

Diglicidyl ether of bisphenol A (BADGE, $n=0$ ) (Resin 332, Sigma Chemical Co., St Louis, USA) and ZnTPyP (Sigma-Aldrich Chemie $\mathrm{GmbH}$, Germany) were used without further purification. The structures of these compounds are shown in Fig. 1.

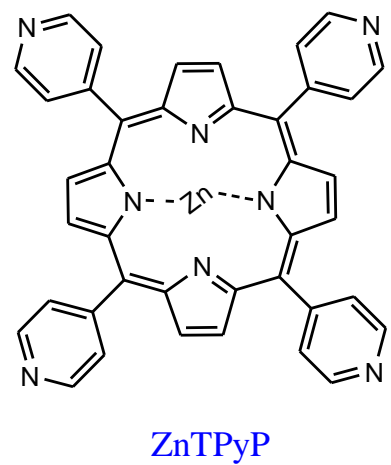

BADGE $n=0$<smiles>c1cc(OCC2CO2)ccc1Cc1ccc(OCC2CO2)cc1</smiles>

Figure 1.Structures of BADGE, $n=0$ and ZnTPyP.

First, epoxy resin and curing agent were carefully and homogeneouslymixed at the 9:1 ( $\mathrm{mol} / \mathrm{mol})$ ratio at room temperature. Second, a sample ofthis mixture (typically 8-10 mg) was encapsulated in aluminumpans for the differential scanning calorimeter (DSC) analysis. The optimum (BADGE, $\mathrm{n}=0$ )/ZnTPyP ratio was determined bycuring experiments at different values of the epoxy/curingagent ratio by the dynamic method. The curing reaction was programmed between $50^{\circ} \mathrm{C}$ and $350^{\circ} \mathrm{C}$ at a heating rate of $10^{\circ} \mathrm{C} / \mathrm{min}$.

FTIR

The curing process was monitored with anVarian 670-IR spectrophotometer with aresolution of $4 \mathrm{~cm}^{-1}$.Furthermore, an attenuated total reflection accessory with adiamond crystal (PIKE GladiATR; range: $4000-100 \mathrm{~cm}^{-1}$ ) was used to determineFTIR spectra.

\section{RESULTS AND DISCUSSION}


The vibration band at $915 \mathrm{~cm}^{-1}$ has been chosen as areference band for the different vibration bands of the epoxygroups $\left(760,915\right.$, and $\left.970 \mathrm{~cm}^{-1}\right)$.Figure 2 shows the infrared spectra of the epoxy resin BADGE $n=0$ (blue line), the epoxy systemheatedfrom $50^{\circ} \mathrm{C}$ to $230^{\circ} \mathrm{C}$ (red line) and the epoxy system heated from $50^{\circ} \mathrm{C}$ to $350^{\circ} \mathrm{C}$ (purple line). It can be seen that the intensity of the vibration band of the terminal epoxy groups decreases during the curing reaction; at the same time $v\left(\mathrm{OH}^{-}\right)$at $3450 \mathrm{~cm}^{-1}$ increases in intensity. The ring-opening of the epoxy group generates a strong band at about $1130 \mathrm{~cm}^{-1}$ assigned to the asymmetric $\mathrm{C}-\mathrm{O}-\mathrm{C}$ stretching vibration ${ }^{14}$. The band at $710 \mathrm{~cm}^{-1}$ assigned to the stretching vibrations of $\mathrm{C}-\mathrm{H}$ bonds in a pyridine ring practically disappears, suggesting that the pyridine ringswere destroyed upon reacting with BADGE $n=0$. At thesame time, new bandsappear at 1470 and $1650 \mathrm{~cm}^{-1}$, which could be assigned to the carbonyl of pyridone and the unconjugated carbon double bonds. Therefore the tertiary amine ZnTPYP not only initiates the homopolimerization reaction but also reacts with the resin forming pyridone.
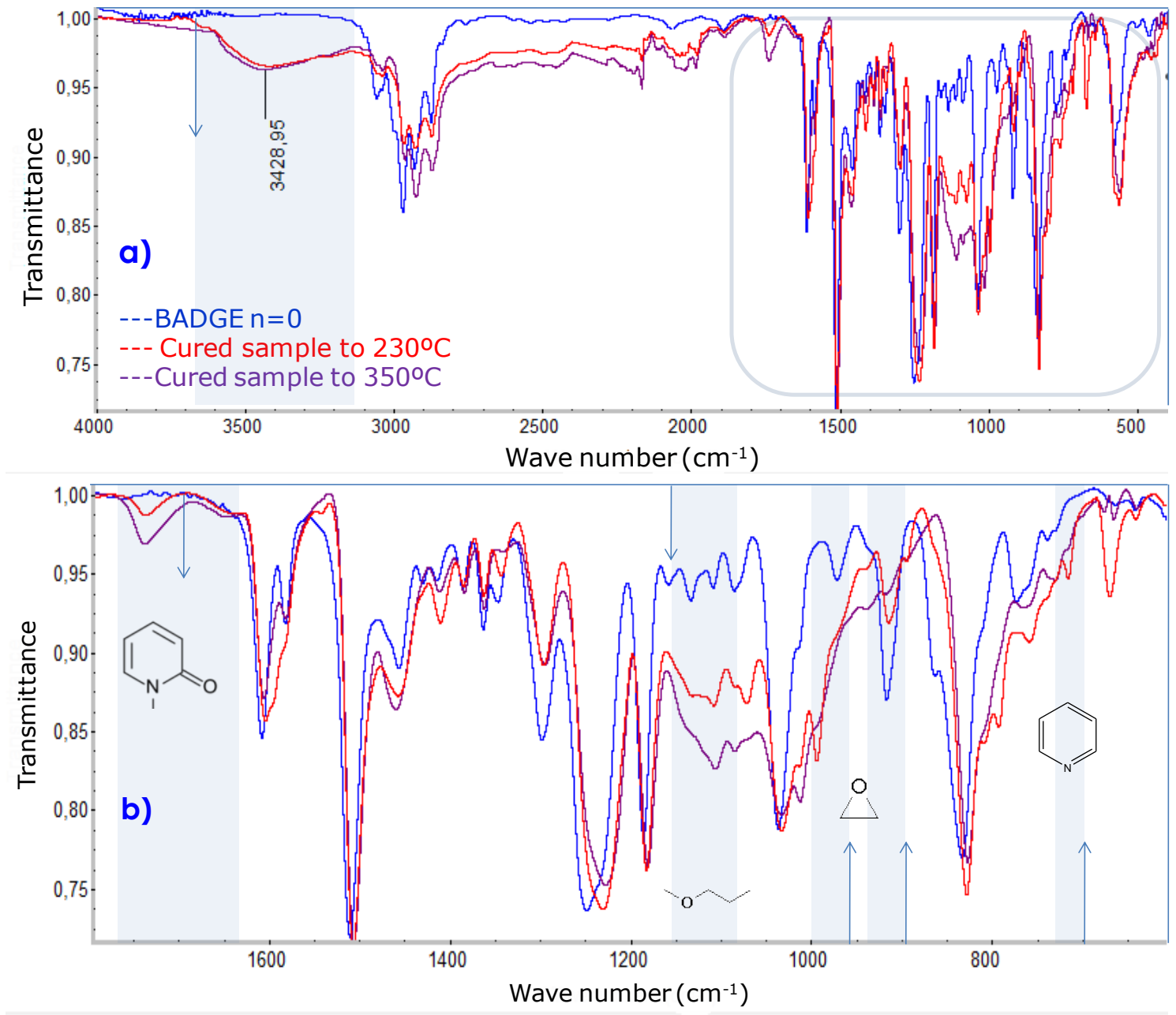

Figure 2.a)Comparison of FTIR spectra of BADGE $n=0$ (blue line), the epoxy systemheatedfrom $50^{\circ} \mathrm{C}$ to $230^{\circ} \mathrm{C}$ (red line) and the epoxy system heated from $50^{\circ} \mathrm{C}$ to $350^{\circ} \mathrm{C}$ (purple line); b) FTIRspectra enlargement between 1800 and $600 \mathrm{~cm}^{-1}$.

It is proposed that epoxy groups of BADGE $n=0$ could be involved in two reactionsduring the curing process. At the same time that epoxy groups react with the pyridine rings (Figure 3), the homopolymerization mechanism of the epoxy groups could 
appearwhich implies the formation of aliphatic ethers (Figure 4). Both reactions could be catalyzed by zinc, which would act as a Lewis acid.

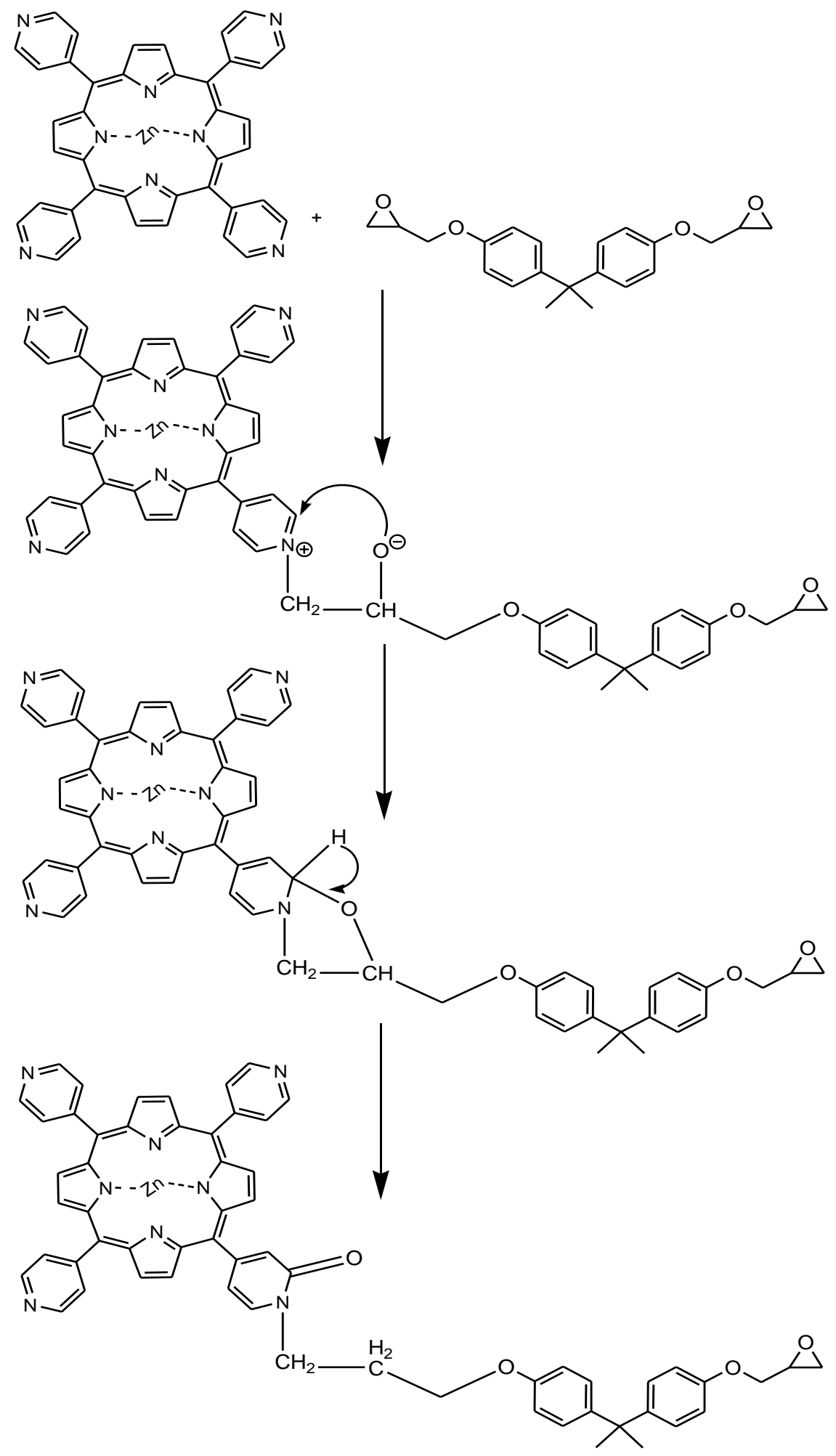

Figure 3.Proposed mechanism for the heteropolymerization. Formation of the pyridone.

The reaction was initiated by the nucleophilic attackof the tertiary nitrogen atom of ZnTPYP on the epoxide groups of BADGE, forming a salt. In the second step, the 
oxygen ion immediately attacks the $\alpha$-position ofpyridine ring and the aromatic structure of pyridinering is destroyed, forming pyridone ${ }^{23}$.

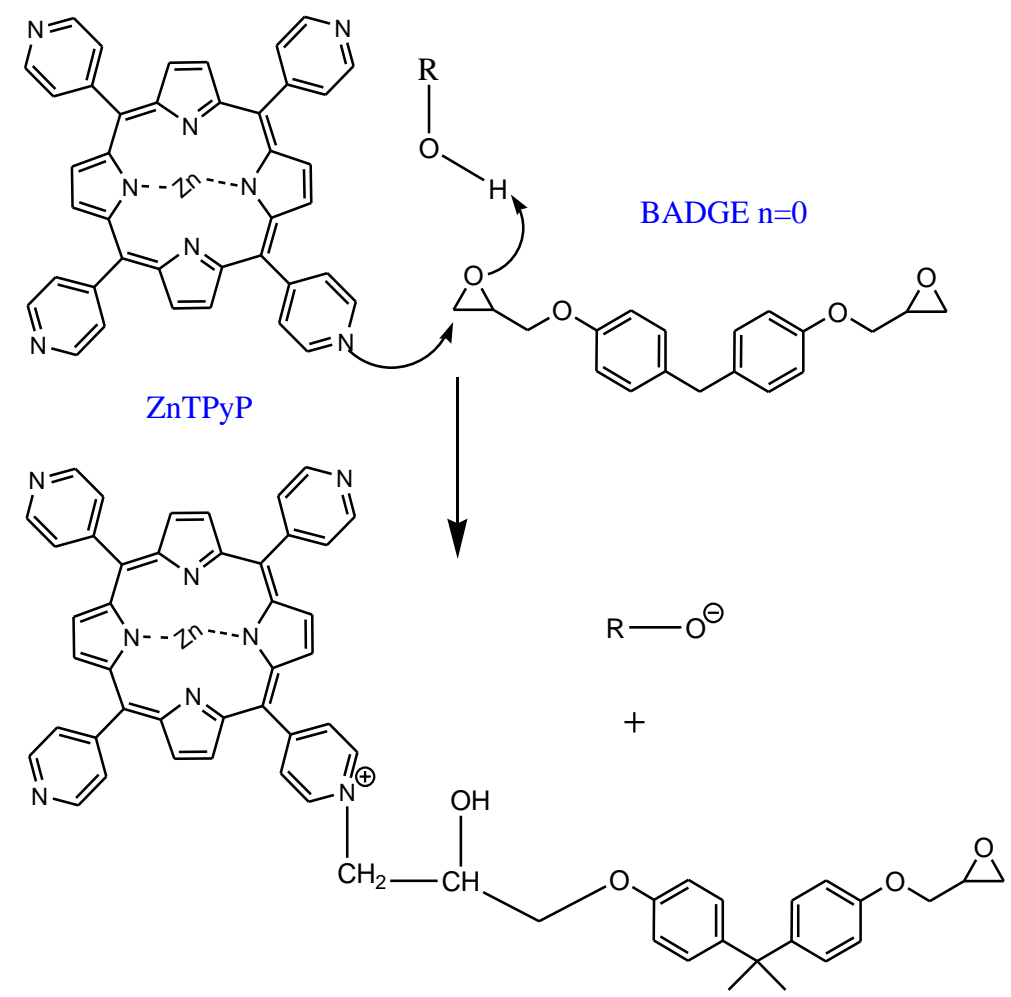

Figure 4.Proposed mechanism for the homopolymerization

It is proposed that the homopolymerization of epoxide groups could be initiated by the nitrogen atoms of pyridine rings ${ }^{24}$. Note that the homopolimerizationunder identical conditions but in the absence ofZnTPyP, is a fairly slow process.

A semi-empirical quantum chemistry program was used for verifying the occurrence of the pyridone formation. Various molecular properties of different chemical structures werecalculated for predicting thebehavior of the system. The choice of method (semi-empirical or ab-initio) is a key factor to calculate the structures and properties of molecules and solids. Both ab initio and semi-empirical approaches involve approximations. The ab-initio methods are more accurate but need more computer time; whereas simplifications introduced by semi-empirical approaches assume that the chemical behavior exclusively depends on the valence shell, not including internal electrons.

The software MOPAC2012 25 was chosen in order to make all the calculations needed for this study. Different Hamiltonians available inMOPAC2012 (AM1, PM3, MNDO, PM5, PM6 and PM7) were used for studying the1-methyl-2-pyridone, used as a model compound for assessingthe validity and reliability of the calculated vibration frequencies. Experimental data of 1-methyl-2-pyridone are shown in Figure 5. 


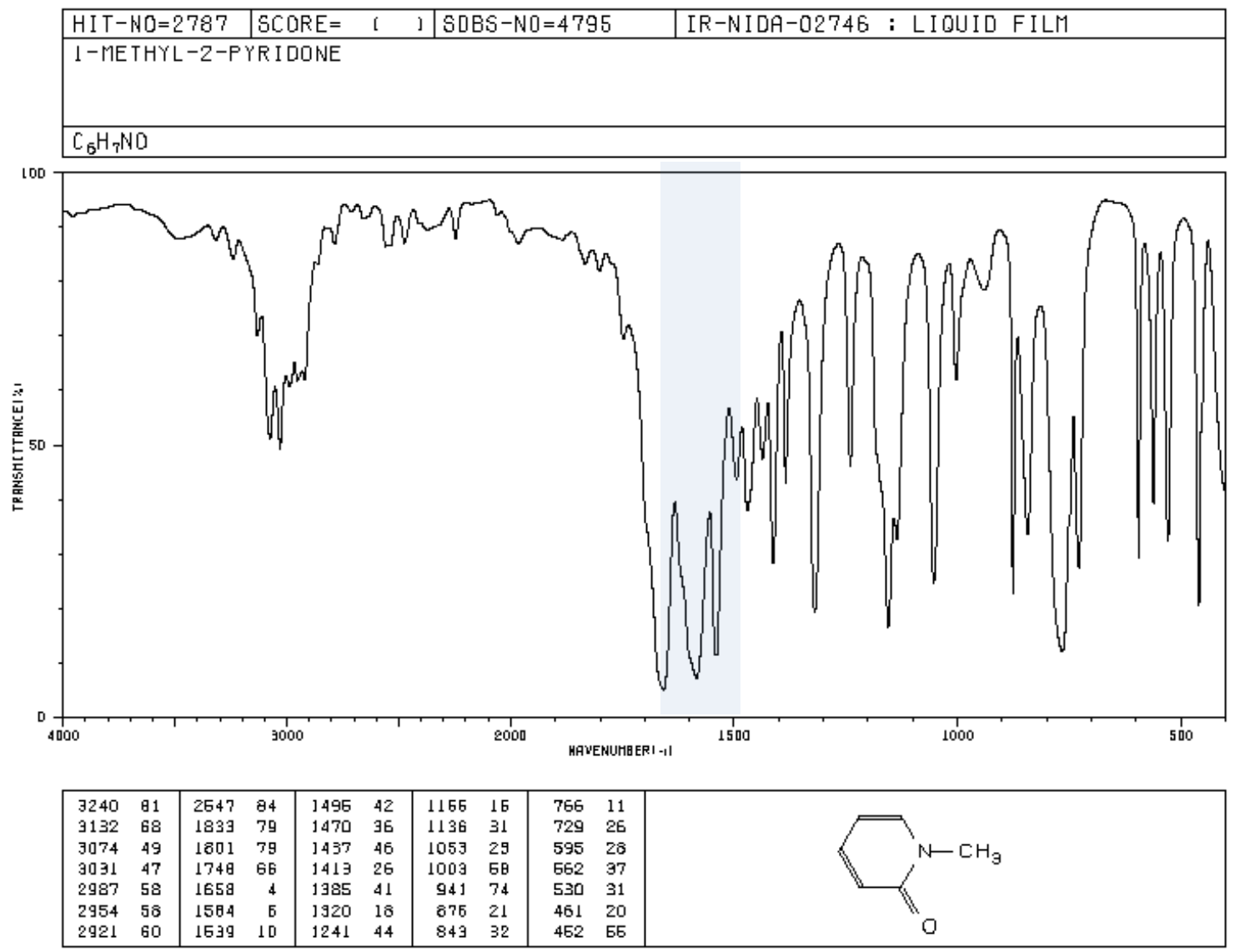

Figure5.ExperimentalFTIR spectrum of 1-methyl-2-pyridone( SDBSNo. 4795).

Obtained values for the $\mathrm{C}=\mathrm{O}$ vibrationare given in Table 1. The best agreement between the calculated and experimental values is obtained withthe RMI semiempirical Hamiltonian. However, this method is not parameterized for Zinc, so the PM6 model was chosen for calculations with the simplified model molecule shown in Figure 6, which after minimization rendered the structure shown in Figure 7, over which the oscillation frequencies were calculated.

Table 1.Values for the $C=O$ vibrationobtained using the different Hamiltonians available inMOPAC2012.

\begin{tabular}{lc}
\hline Hamiltonians & Vibration $\mathbf{C}=\mathbf{O}\left(\mathbf{c m}^{-1}\right)$ \\
\hline AM1 & 1992,06 \\
pm3 & 1903,76 \\
pm5 & 1827,88 \\
PM6 & 1778,2 \\
PM7 & 1830,28 \\
MNDO & 2087,9 \\
RM1 & 1762,39 \\
MNDOD & 2088,04
\end{tabular}




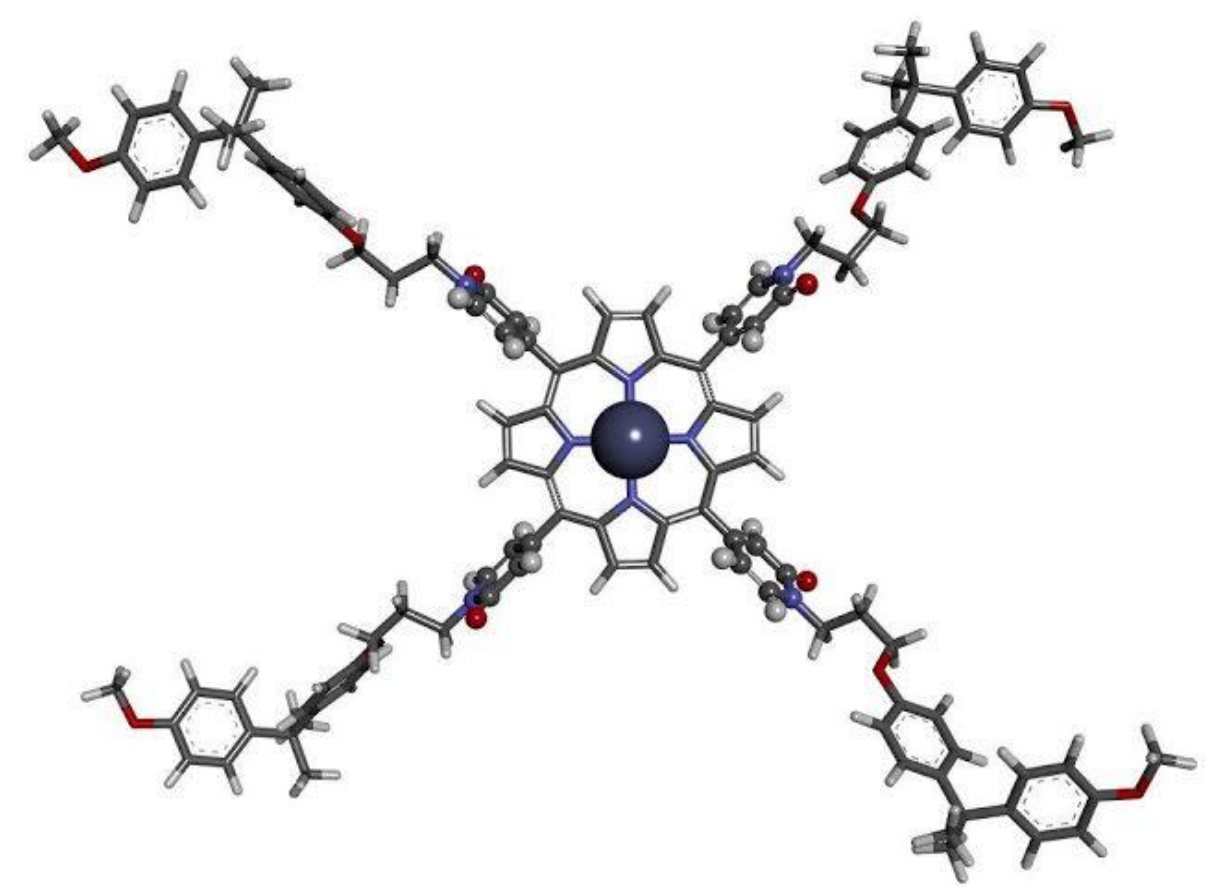

Figure 7. Minimized structure used for calculating the $I R$ frequencies

The Table 2 shows the theoretical results for the stretching vibration of the lactam carbonyl group. Values fall between 1782 and $1785 \mathrm{~cm}^{-1}$. It perfectly matches with experimental values for the epoxy resin. 
Table 2.Stretching vibration of the carbonyl group inlactams

\begin{tabular}{cl}
\hline VIBRATION & ATOM PAIR \\
\hline 1781.90 & C $45-$ O 52 \\
1782.30 & C $42--$ O 95 \\
1783.02 & C $30--$ O 50 \\
1785.44 & C $30--$ O 50 \\
\hline
\end{tabular}

\section{CONCLUSIONS}

Simultaneous use of FTIR technique and theoretical calculations by means of standard semiempirical software can help elucidating the curing process as well as the products obtained when macrocycles are used for curing epoxy resins.

\section{ACKNOWLEDGMENTS}

The authors thank the Ministerio de Ciencia y Tecnolog_la, Spain, Project MAT201029440 for financial support. EVB also thanks Dr. Senén Paz and GAIRESA for a scholarship.

\section{REFERENCES}

(1) Fraga, F.; Vázquez, E. C.; Rodríguez-Núñez, E.; Martínez-Ageitos, J. M. Polym. Adv. Tech. 2008, 19, 1623.

(2) Mauzerall, D. C. Clin. Dermatol. 1998, 16, 7.

(3) Drain, C. M.; Varotto, A.; Radivojevic, I. Chem. Rev. 2009, 109, 29.

(4) Molecular Mechanisms of Photosynthesis:

; Blankenship, R. E., Ed. Oxford, 2002.

(5) Feng Bai, Z. S., Huimeng Wu, Raid E. Haddad, Eric N. Coker, Jian Yu Huang, Mark A. Rodriguez and Hongyou Fan Nano Lett. 2011, 11.

(6) M. S. Heise, G. C. M. Macromolecules, , 22 (1), pp 99-104 1989, 22, 6. $39,18$.

(7) Martin, M. S. H. a. G. C. Journal of Applied Polymer Science 1990,

(8) S.K. Ooi, W. D. C., G.P. Simon, C.H. Such 2000, $41,11$.

(9) Rozenberg, B. A. Advances in Polymer Science 1986, 75, 53.

(10) Matejka, L., Podzimek, Stepan, Simonsick Jr., William J., Spacek, Pavel, Dusek, Karel Journal of Polymer Science, Part A: Polymer Chemistry 1992, $30,12$.

(11) K Fryauf, V. S., M Fedtke 1993, 34, 5.

(12) Barton J. M., B. G. J., Hamerton I., Howlin B. J., Jones, J. R.; S., a. L. J. Mater. Chem.1994, 4. 
(13) John M. Barton, I. H., Brendan J. Howlin, John R. Jones and Shuyuan LiU POLYMER 1998, 39, 9.

(14) Williams, I. E. D. E. a. R. J. J. Polymer Engineering \& Science 2006 , $46,9$.

(15) Fernández-Francos, X., Cook, W.D., Salla, J.M., Serra, À., Ramis, X Polymer International 2009, 58, 10.

(16) Xavier Fernández-Francos, W. D. C., Àngels Serra, Xavier Ramis, Genhai G. Liang, Josep M. Salla Polymer 2010, 51, 9.

(17) Silvia G. Prolongo, G. d. R., Alejandro Ureña International Journal of Adhesion and Adhesives 2006, 26, 8.

(18) Fiore Ricciardi, W. A. R., Madeleine M. Joullié Journal of Polymer Science: Polymer Chemistry Edition 1983, 21, 16.

(19) John M. Barton, I. H., Brendan J. Howlin, John R. Jones, Shuyuan Liu Polym. Int.1996, 41, 10.

(20) Xavier Fernández-Francos, D. S., Francesc Ferrando, Xavier Ramis, Josep M. Salla, Àngels Serra, Marco Sangermano Journal of Polymer Science Part B: Polymer Physics 2012, 50, 15.

25,7 .

(21) Roberto J. J. Williams, C. C. R., Karel Dušek Polymer Bulletin 1991,

(22) Vázquez, E. C.; Fraga, F.; Martínez-Ageitos, J. M.; Vázquez Tato, J. J. Appl. Polym. Sci. 2013.

(23) XUE Gi, J. S. Chinese Journal of Polymer Science (C JPS) 1987, 5, 8.

(24) FANLIANG MENG, W. Z., SIXUN ZHENG JOURNAL OF MATERIALS SCIENCE 2005, 40, 7.

(25) a) Versión 15.089W 64BITS, MOPAC2012, James J. P. Stewart, Stewart Computational Chemistry, Colorado Springs, CO, USA, HTTP://OpenMOPAC.net ed. b) Maia, J.D.C., et al., J. Chem. Theory Comput. 2012, 8, 3072-3081. 